\title{
Discurso y comunicación intercultural como sustento epistemológico para una educación en contexto indígena
}

\section{Discourse and intercultural communication as epistemological basis for education in indian context}

Recepción: Diciembre - 2008

Aprobación: Mayo - 2009

María Eugenia Merino Dickinson*

\section{RESUMEN}

Este trabajo discute las nociones de discurso y comunicación intercultural como sustento epistemológico de base para una educación intercultural en contexto indígena, desde la perspectiva del discurso como articulador y configurador del sujeto en tanto ente sociocultural y sociohistórico y como producto del discurso en permanente construcción. Se plantea una educación intercultural, sustentada en los principios de la comunicación intercultural donde estudiantes de la cultura mapuche y la cultura chilena intercambian sus respectivos significados culturales mediante procesos de negociación de identidad cultural y apoyados por el profesor en el aula, redundando en una identidad cultural y étnica positiva en los niños de escuelas básicas en contexto indígena de la Región de La Araucanía.

PALABRAS CLAVE: Discurso; educación intercultural; contexto indígena

\section{ABSTRACT}

This work develops the notion of discourse as epistemological basis for an intercultural education in indigenous contexts, where discourse is seen as a sociocultural and sociohistoric articulator and performative of the subject, and as product in permanent construction. Based on the principles of intercultural communication a notion of intercultural education is posited where students from the Mapuche and Chilean cultures exchange their respective cultural meanings through the negotiation of their cultural identities, a process that is supported and enhanced by the teacher within elementary schools at the Araucanía region.

KEY WORDS: Discourse, intercultural education; indigenous context

\footnotetext{
* Lingüista y Doctora en Ciencias Humanas, académica de la Facultad de Educación de la Universidad Católica de Temuco. Correo:mmerino@uct.cl
} 


\section{Introducción}

En el marco de la educación intercultural propuesta por el proyecto Milenio $\mathrm{N}^{\circ}$ $039^{1}$, cuyo objetivo principal es evaluar el método educativo de escuelas básicas en la Región de La Araucanía, asociadas con población mapuche y desarrollar propuestas para la implementación de una educación intercultural en contexto indígena, el discurso se posiciona como una disciplina fundamental que permitirá aportar a la implementación de cualquier programa o propuesta de educación intercultural, particularmente desde el discurso pedagógico en contexto intercultural. Es por ello que el propósito de este artículo es reflexionar acerca del estatus del discurso y su rol en la comunicación intercultural con miras a un currículo de educación intercultural, y plantear los principios básicos a considerar en una propuesta de educación intercultural en contexto indígena mapuche.

\section{El estatus reivindicado del discurso}

En la antigua Grecia el énfasis de los estudios sobre el discurso estuvo focalizado principalmente en conocimiento del lenguaje como un fin en sí; el lenguaje es inmanente, poseedor de su propia estructura y en él se encuentra el sentido de la comunicación humana. Bajo este paradigma, ser culto y educado implicaba el estudio del latín y su gramática, junto con la dialéctica y la retórica como instrumentos de argumentación y persuasión sociopolítica. Nace entonces el enfoque estructuralista de los estudios del lenguaje. Este énfasis permanece y se acentúa más tarde en las diversas escuelas del lenguaje que dominaron particularmente en Europa y Norteamérica hasta mediados del siglo XX con Ferdinand de Saussure como su máximo exponente.

Más tarde y desafiando la poderosa fuerza del estructuralismo, surge una corriente que diverge en términos de la concepción del lenguaje: el lenguaje utiliza significados, tiene una función, y se realiza mediante acciones verbales y no verbales. Figuras icónicas fueron en este movimiento Austin y Searle con la Fi- losofía del Lenguaje Ordinario y su teoría de los Actos de Habla en Inglaterra, y Halliday en Norteamérica con las funciones simples y complejas del lenguaje. No obstante, durante todo este período el sentido de la comunicación humana continúa atribuyéndosele al lenguaje, el que retiene su carácter de inmanente y su foco en el hablante como usuario de este.

No fue sino a partir de los años 70 que desde las ciencias sociales y las humanidades surgen los enfoques postestructuralistas que influyeron de manera determinante en la reflexión en torno al rol del discurso en las relaciones interpersonales e intergrupales del hombre en sociedad. Este giro epistemológico reconoce al discurso su rol articulador y configurador del sujeto en tanto ente sociocultural y sociohistórico y como producto del discurso en permanente construcción. Las postrimerías del siglo XX finalmente posicionan al discurso su verdadero significado y función, el discurso como discurrere, vocablo latín que define un 'traspaso' de algo que circula de una persona a otra, y que se realiza mediante un texere o texto conformado por unidades de significado que son entretejidos para construir una unidad mayor.

En este sentido, diversas teorías sobre el discurso desde la lingüística, la sociología y la filosofía aportaron a la reconstrucción del estatus y el significado del discurso. Por ejemplo, la ecuación 'sujeto y sujeto del habla' de Benveniste (1974), que adscribe al discurso dos componentes que se agregan y desagregan en su interior: quien habla y quien es sujeto de su propia habla constituyen el discurso. Desde las prácticas sociales el discurso interpela al sujeto y activa las ideologías subyacentes en su discurso, el sujeto es para Althusser (1971) un efecto de la interpelación ideológica. Para Foucault (1984), a partir de las prácticas sociales se conforman sujetos sociales específicos cuyos respectivos 'órdenes del discurso' determinarán la inclusión/exclusión de los discursos en el orden social. Finalmente la deconstrucción o descentramiento del lenguaje como centro del significado propuesto por Derrida (2000) inscribe al sujeto como función de su propio lenguaje. 
El objetivo del estudio del discurso se orienta en esta nueva mirada hacia la detección de las reglas que subyacen la interacción simbólica en la comunicación humana y el conocimiento acerca de cómo el sujeto (re) construye su realidad a partir del discurso. En resumen, este giro construccionista postestructuralista de los estudios del discurso puso en tela de juicio la inmanencia del lenguaje que caracterizó por siglos a la era estructuralista.

\section{Discurso y comunicación intercultural en contextos locales}

En la actualidad, prácticamente todas las sociedades del planeta poseen un carácter multiétnico y multicultural, coexistiendo de manera permanente diferentes grupos étnicos, religiosos, lingüísticos, y donde la calidad de sus relaciones constituye el elemento fundamental de la convivencia humana. Los distintos grupos humanos necesitan hoy día ponerse de acuerdo para resolver oportunamente los graves problemas de impacto global que enfrentan.

Para comprender las relaciones entre distintos grupos culturales al interior de la sociedad latinoamericana debe tenerse presente el contexto en el que se desarrollaron los primeros contactos indígena-europeo. Este contacto generó una forma distintiva de relación interétnica donde el estatus del contacto lo otorga la llegada del europeo, quien inmigraba al nuevo continente e imponía sus reglas, normas y cultura a los grupos originarios. Se iniciaba así un tipo de relación interétnica e intercultural de fuerte dominación del europeo hacia el indígena y posteriormente hacia los grupos mestizos y criollos. Los tipos de contacto que se generaron pueden analizarse dentro de un continuum de variadas intensidades: desde contactos armónicos y de aceptación y reconocimiento del otro grupo, como es el caso de Paraguay y México, hasta contactos traumáticos que dejaron huellas y cicatrices a su paso, transmitiéndose de generación en generación con sus consabidas consecuencias, como es Brasil, Venezuela, Colombia, Chile y Argentina.

Estos contactos fueron necesariamente articulados mediante la comunicación verbal a través del discurso. ¿Qué tipo de discurso manejaron los primeros interlocutores interétnicos en el nuevo continente? Obviamente se trató de un discurso intercultural que se apoyó en el uso de intérpretes indígenas (yanaconas en la cultura mapuche por ejemplo), o bien europeos lingüísticamente dotados que manejaban las dos lenguas en contacto; como asimismo el uso de hablas pidgin o criollas que permitieron tender los primeros puentes comunicativos interpersonales e intergrupales. El resultado de estos primeros encuentros grupales fijó dos caminos distintos, dependiendo de los intereses económicos, políticos, religiosos y sociales del grupo visitante y de cómo estos elementos fueron constituyendo la ideología de las relaciones interétnicas y los diferentes modos de dominancia y/o respeto por las culturas indígenas residentes en el continente americano. Nacen en ese entonces los primeros atisbos de una comunicación intercultural que fijaría el tipo de relación interétnica e intercultural y el devenir histórico de cada pueblo. Algunas relaciones se movieron hacia la armonía y la simetría, como Paraguay por ejemplo, en tanto otras se localizaron más hacia el otro extremo del continuum, como es el caso de Chile.

Relevamos aquí el concepto de interculturalidad que aporta la clave para enfrentar con éxito relaciones más armónicas y equilibradas entre los grupos humanos. Interculturalidad describe el fenómeno de las relaciones y encuentros entre grupos humanos que tienen diferentes maneras de pensar, sentir y actuar; no debe confundirse con lo interétnico que más bien se focaliza en la relación entre grupos que se reconocen poseedores de una identidad étnica particular. La interculturalidad no admite asimetrías, es decir, desigualdades entre culturas mediadas por el poder. Para Ting-Toomey (1999) estudiar las relaciones interculturales es analizar el encuentro interpersonal, intercomunitario o internacional de personas o grupos pertenecientes a pueblos con culturas diferentes. Es la otredad que se manifiesta en las relaciones intergrupales, es decir, aquellas cualidades que son diferentes de las nuestras y que no forman parte de los grupos a los cuales pertenecemos, pero que están presentes en otros individuos y grupos (Rosener citado por Ting-Toomey, op. cit.). De este modo los 'otros' constituye una conceptualización acerca de las personas que son diferentes a nosotros en una o varias dimensiones tales como edad, etnicidad, raza, orientación sexual, afecto, entre otros. 
A este respecto, Loden y Rosener (en Ting-Toomey, op. cit.) definen dos dimensiones que contribuyen a la forma en que los grupos de personas pueden diferir unos de otros al interior de cualquier cultura. La dimensión primaria engloba las diferencias humanas de nacimiento $\mathrm{y} / \mathrm{o}$ que ejercen un impacto importante en nuestra socialización temprana y un impacto permanente en nuestras vidas, como son por ejemplo la etnicidad, género, edad, clase social, habilidades físicas y orientación sexual. Estas son las que moldean y modelan nuestra autoimagen y dirigen nuestros sentimientos, pensamientos y conducta. Además, los miembros de otros grupos a menudo interactúan con nosotros basados en las imágenes estereotípicas construidas sobre la base de tales diferencias. La dimensión secundaria por su parte refiere a las condiciones que pueden ser modificadas más fácilmente que las primarias,. como son la educación, la experiencia laboral, los ingresos, la movilidad social.

La comunicación intercultural se yergue como una poderosa herramienta sociolinguística que pemite acercar a los miembros de grupos y culturas distintas para compatibilizar las características propias de las dimensiones primarias y secundarias con el propósito de comunicarse de manera eficiente. TingToomey define la comunicación intercultural como "el proceso de intercambio simbólico mediante el cual individuos de dos (o más) comunidades culturales diferentes negocian significados compartidos en una situación interactiva" (op. cit.:16). En la comunicación intercultural, el grado de diferencia entre individuos se deriva principalmente de factores de membresía grupal tales como creencias, valores, normas y patrones de interacción. La comunicación intercultural ocurre cuando alguno de dichos factores afecta nuestro proceso de comunicación, tanto a nivel consciente como inconsciente.

Según esta autora, la comunicación intercultural se compone de cuatro dimensiones principales. En primer lugar el intercambio simbólico apunta al uso de símbolos verbales o no verbales por parte de uno o más individuos para lograr significados compartidos. Los símbolos verbales representan el contenido de dicho proceso de intercambio de mensaje, en tanto los no verbales o claves representan los aspectos analógicos o significados afectivos de la comunicación.

En segundo término, la comunicación intercultural apunta a la naturaleza transaccional y la irreversibilidad de la comunicación. Ello significa que comunicarse es intercambiar objetos, en este caso significados y mensajes que se dan a un receptor como parte de un intercambio; asimismo, la comunicación de una idea o proposición no puede ser revertida en términos del impacto acústico, expectativa y respuesta estimulada en el receptor (lo que Searle (1979) denominó los componentes intake y perlocucionario de todo acto de habla).

Una tercera dimensión son las comunidades culturales diferentes, entendiendo estas como un grupo de individuos interactuantes dentro de una unidad limitada adscritos a un conjunto de tradiciones, creencias, valores y forma de vida compartidas.

Finalmente, la negociación de significados compartidos constituye la meta principal de cualquier encuentro de comunicación intercultural para que el mensaje sea entendido. 'Negociar' connota la naturaleza creativa de dar y tomar como proceso fluido en la comunicación humana. Si se considera que todo mensaje contiene múltiples niveles de significado, la comprensión de cómo la gente se expresa en un proceso de comunicación intercultural depende de tres niveles críticos de significado que son el contenido, la identidad y el tipo de relación que se da entre los interactuantes.

Estas cuatro dimensiones de comunicación intercultural son materializadas mediante el discurso. De acuerdo con Ting-Toomey (op. cit.), para enfrentar con éxito el estudio y práctica de la comunicación intercultural un enfoque discursivo se debe basar en tres principios teóricos básicos:

Principio 1: toda comunicación intercultural se realiza mediante varios códigos de comunicación. El discurso constituye su eje articulador.

Principio 2: la comunicación intercultural se expresa mediante acciones sociales más 
que por sistemas de representación de pensamientos y valores:

la unidad básica de análisis es el sistema cultural de significados (lingüísticos y no linguísticos) de ambos grupos en interacción.

la comunicación emerge de las prácticas sociales: se deben hacer conscientes las prácticas linguísticas y culturales, porque en general no estamos conscientes sobre cómo nos comunicamos y cómo actuamos a diario, solo sale naturalmente. Ello es muy relevante para la toma de conciencia de las prácticas discursivas prejuiciadas y estereotipadas de un grupo sobre otro.

el habitus como base de la acción comunicativa: la experiencia acumulada que cada individuo posee de su sociedad y de las relaciones intra e intergrupales de sus miembros. Es la historia de vida de una persona hasta el presente.

el posicionamiento identitario: a través del discurso y la acción los participantes realizan de manera implícita o explícita sus respectivos posicionamientos de identidad personal y étnico-cultural.

socialización: todo cuanto un individuo dice lo posiciona como miembro de una comunidad específica y el discurso funciona aquí como la herramienta más poderosa de socialización grupal.

el discurso produce 'otredad': debido al efecto de la socialización, toda comunicación posee el efecto simultáneo de producir 'otros' a quienes identificamos como no miembros de nuestra comunidad de práctica. Socialización y otredad son las dos caras de la moneda de la comunicación intercultural.

Principio 3: la comunicación intercultural activa la respectiva historia, sociedad y cultura de los individuos que participan en dicha comunicación. Se basa en tres conceptos propuestos por Bajtin:

3.1. interdiscursividad: toda comunicación se construye sobre múltiples discursos, superpuestos y en ocasiones contradictorios.
3.2. intertextualidad: toda comunicación (nuestra habla) toma prestado de otros discursos y textos usados previamente, y son reproducidos posteriormente en nuevos discursos.

3.3. dialogismo: toda comunicación responde a comunicaciones previas y anticipan posteriores comunicaciones. Es lo que nos permite hacer inferencias de los discursos.

En resumen, el discurso se constituye en el articulador comunicativo central de los grupos humanos en sociedad, construyendo sus lógicas socioculturales, políticas e ideológicas y regulando y constriñendo sus prácticas sociocomunicativas.

Discurso, comunicación intercultural y educación intercultural

En el contexto de las relaciones interétnicas e interculturales, los miembros de grupos étnicos minoritarios que históricamente han mantenido un bajo estatus social, tienden a estar más conscientes y sensibles respecto de su etnicidad y cultura, como es el caso de los miembros de la cultura mapuche en Chile. De hecho, para los miembros de estos grupos, la dimensión del poder percibida como desequilibrada junto con un acceso desequilibrado a este, los lleva a establecer límites bastante demarcados entre el grupo que ostenta el poder y el grupo marginal dominado (Yinger, 1994; Orbe, 1998; Van Dijk, 1999).

Lo anterior puede conllevar al individuo a una separación o automarginación psicológica y/o física de su proceso de integración social, lo que se hace más notorio en el período escolar y particularmente en su proceso de educación en la escuela básica (Mellor, Merino, Saiz, y Quilaqueo, 2007). Las consecuencias de estos problemas en la educación impactan en magros o nulos resultados en el logro de competencias básicas en la formación de los niños, tal como lo demuestran los resultados de la prueba SIMCE de $4^{\circ}$ Año Básico en Chile (Simce, 2007), lo que se acentúa en escuelas rurales y urbano-marginales con alta población escolar mapuche particularmente en la Región de La Araucanía (Hepp, Dreves y Laval, 2005). 
Estos resultados pueden tener variadas causas. Por una parte, la descontextualización del currículo educacional en contextos indígenas e interculturales puede conducir a que los aprendizajes no resulten significativos para los alumnos; y por otra, la dificultad adicional que significa para los niños mapuches asumir su condición étnica en tanto miembros de una minoría indígena percibida como un grupo de bajo prestigio por la sociedad mayoritaria.

Más aún, resulta gravitante el impacto que ejercen las prácticas frecuentes de prejuicio y discriminación de que son objeto los mapuches por parte de la sociedad no mapuche (Merino y Quilaqueo, 2003; Merino y Quilaqueo, 2004; Merino, Pilleux, Quilaqueo y San Martín, 2007); como asimismo los múltiples efectos psicosociales que dichas prácticas generan en la calidad de vida de los indígenas (Merino, 2007; Merino, Quilaqueo y Saiz, 2008; Merino, Mellor, Quilaqueo y Saiz, 2008; Merino y Mellor, 2008).

Uno de los objetivos que persigue el proyecto Milenio CIECII P076-039-F "Centro de Investigación en educación en Contexto Indígena e Intercultural" es evaluar el método educativo a través del discurso pedagógico de escuelas básicas en la Región de La Araucanía asociadas con población mapuche, para así desarrollar propuestas para la implementación de una educación intercultural en contextos indígenas, considerando las lógicas occidental chilena y los saberes indígenas mapuches, surge el discurso como una disciplina que podrá aportar de manera importante en la implementación de dichas propuestas. Para ello es necesario relevar los beneficios de la comunicación intercultural en la escuela intercultural donde alumnos de dos (o más) comunidades culturales diferentes negocien significados compartidos en situaciones interactivas orientadas por el docente de aula. En toda comunicación intercultural la identidad étnica es un factor clave a tener presente y que es definida como "la lealtad/fidelidad subjetiva hacia un grupo, grande o pequeño, socialmente dominante o subordinado, con el cual se mantienen lazos ancestrales" (TingToomey, op. cit.:32). Esta identidad es inherente a la ascendencia, el ancestro y las creencias acerca de los orígenes de los antepasados y puede basarse en la raza, el origen nacional, la religión, o el idioma. Cuando nos comunicamos interculturalmente con miembros de una cultura diferente, se produce una negociación de la identidad que se define como un proceso de interacción transaccional mediante el cual los individuos en una situación intercultural intentan afirmar, definir, modificar, desafiar y/o respaldar las imágenes deseadas del 'yo', tanto las propias como las de los demás.

Del mismo modo, dependiendo del contexto en que se desarrolla la comunicación intercultural, los comunicantes intentan evocar en la interacción sus propias identidades deseadas, como también desafiar o respaldar las identidades de los otros. Por tanto, la negociación de identidad se centra en la percepción que maneja el individuo respecto de la seguridad versus vulnerabilidad de su identidad como la base que afecta los encuentros interculturales. En este sentido, el aspecto cultural juega un rol fundamental en la visión que construimos de nosotros mismos ya que los individuos tienden a sentirse seguros cuando se comunican con personas a quienes perciben como no amenazantes a su identidad y con un alto sentimiento de familiaridad (TingToomey, op. cit.).

La negociación de identidad en la comunicación intercultural es tarea prioritaria de la escuela, lo que puede lograrse de manera eficiente mediante el uso y manejo de un discurso adecuado en contexto intercultural. La escuela chilena actual regularmente no reconoce los fundamentos epistemológicos que poseen las culturas indígenas y que se expresan en prácticas culturales, saberes y conocimientos propios. No obstante, los actuales procesos de globalización obligan a repensar y retrabajar las relaciones entre sociedad y cultura en una doble perspectiva: de un trabajo de apertura al 'otro' y de un análisis y redefinición de los conceptos utilizados como referencia en la sociedad chilena.

En consecuencia, una educación intercultural, basada en los principios de la comunicación intercultural y en la negociación de la identidad, constituye un desafío para la escolarización de las sociedades indígenas y no indígenas porque permite la confrontación de las personas pertenecientes a esferas cul- 
turales diferentes, lo que relativiza, de algún modo, los conocimientos y obliga a construir un saber multipolarizado (Godenzi 1996).

Finalmente, el supuesto pedagógico que planteo es que una educación intercultural, sustentada en un diálogo discursivo entre la cultura mapuche y la cultura chilena, donde sus miembros intercambian sus respectivos significados culturales mediante procesos de negociación de identidad cultural e imagen y apoyados por el profesor en el aula, redundará en una identidad cultural y étnica positiva en los niños. Ello debiera desarrollarse en ambientes culturalmente familiares y contextos de relaciones cercanas significativas, y mediante el uso de estrategias didácticas que incorporen la diversidad étnico-cultural.

Estas prácticas didácticas permitirán al niño intercultural experimentar seguridad y confianza en su identidad de membresía cultural, sentirse incluido, desear el contacto interpersonal, percibir estabilidad de su identidad en situaciones culturales predecibles y adquirir nuevos conocimientos sobre la base de referentes culturalmente significativos. 


\section{BIBLIOGRAFÍA}

AUSTIN, J. (1975) How to Do Things with Words, eds. J. Urmson y M. Sbisa. Cambridge, MA: Harvard University Press.

ALTHUSSER, L. (1971) Ideology and Ideological state apparatuses, en L. Althuser (ed.), Lenin and Philosophy and Other Essays, London: New Left Books.

BENVENISTE, E. (1974) Problemas de Lingüística General. Editorial Siglo XXI, México.

DERRIDA J. (1994) Jacques Derrida. Edit. John Lechte, Routledge.

Foucault, M. (1984) El Orden del Discurso. Representaciones Editoriales, S.A., México

GODENZI, J. (1996). Educación e interculturalidad en Los Andes y la Amazonía. Cuzco: Centro de Estudios Regionales, Andinos Bartolomé de Las Casas.

HEPP, P. y E. LAVAL (2003). ICT for rural education: A developing country perspective. Learning in School, Home and Community. ICT for Early and Elementary Education. G. M. Y. Katz. Boston, Kluwer.

MELLOR, D.; MERINO, M., SAIZ, J. L. y QUILAQUEO, D. (2009) Emotional reactions, coping and long term consequences of perceived discrimination among the Mapuche people of Chile, Journal of Community and Applied Social Psychology. $\mathrm{N}^{\mathrm{a}}$ 19: 473-491 (2009)

MERINO, M. y QUILAQUEO, D. (2003). Ethnic prejudice against Mapuche in the discourse of members of Chilean society as a reflection of the racialist ideology of the Spanish conqueror. American Indian Culture and Research Journal, 7 (4), 105-116.
MERINO, M. \& QUILAQUEO, D. (2004). Estereotipos y prejuicio étnico hacia los mapuches en textos complementarios a la asignatura de Historia. Campo Abierto, 23, 119-138.

MERINO, M. (2007) El discurso de la discriminación percibida en Mapuches de Chile, Discurso y Sociedad, Vol. 1, N 4, 604-22.

MERINO, M.; PILLEUX, M.; QUILAQUEO, D., y SAN MARTÍN, B. (2007). Racismo discursivo en Chile. El caso mapuche. En T. Van Dijk (ed.), Racismo y Discurso en América Latina (pp. 137-180). Barcelona: Gedisa Editorial.

MERINO, M.; QUILAQUEO, D. y SAIZ, J. L. (2008) Tipología del discurso de la discriminación percibida en Mapuches de Chile, Signos, Vol. 41 (676).

MERINO, M., MELLOR, D. (2008) Perceived discrimination in Mapuche discourse: Contemporary racism in Chilean society, Critical Discourse Studies. Aceptado.

ORBE, M. (1998). Constructing co-cultural theory: an explication of culture, power, and communition, Sage, Thousand Oaks, CA.

SAUSSURE, F. (2004). Problemas de Linguística General. Editorial Siglo Veintiuno, Mexico.

SEARLE, J. (1979). Speech acts. New York: Cambridge University Press.

TING-TOOMEY, S. (1999). Communicating across cultures. The Guilford Press, New York.

VAN DIJK, T. (1999). Ideology: A Multidisciplinary Approach. Sage Publications Ltd.

YINGER, J. M. (1994). Ethnicity. Source of Strenght? Source of Conflict? Suny Press. 